\title{
PENTINGNYA POSBINDU KELILING DALAM MENDETEKSI PENYAKIT TIDAK MENULAR DI RW. 05, KELURAHAN KEDAUNG KALIANGKE
}

\section{Yohanes Firmansyah", Desi Natalia Ginting ${ }^{2}$, Ernawati $\mathrm{Su}^{3}$, Yana Sylvana ${ }^{4}$, Welhan Chau ${ }^{5}$, Pinka Nurashri Setyati ${ }^{6}$}

\author{
1,4,5,6 Dokter Internship RSUD Kalideres, Jakarta \\ Email: yohanesfirmansyah28@gmail.com \\ ${ }^{2}$ Kepala Puskesmas Kelurahan Kedaung Kaliangke \\ Email: desinatalia.ginting@yahoo.com
}

${ }^{3}$ Bagian Ilmu Kesehatan Masyarakat, Universitas Tarumanagara, Jakarta

Email:dr.ernawati@gmail.com

Masuk: 17-12-2019, revisi: 12-05-2020, diterima untuk diterbitkan: 04-06-2020

\begin{abstract}
ABSTRAK
Penyakit tidak menular (PTM) khususnya hipertensi dan penyakit kardiovaskuler telah menjadi penyebab kematian tertinggi di dunia dengan angka mortalitas sembilan juta kematian (44\% dari semua kematian penyakit tidak menular dan $31 \%$ dari semua penyebab kematian global). Tujuan penelitian untuk mengetahui efektivitas dari kegiatan Posbindu PTM Keliling Kampung dalam surveilans faktor risiko dan deteksi dini PTM. Metode: Potong lintang pada masyarakat RW 05 Kelurahan Kedaung Kaliangke, serta data penelitian di uji dengan uji Chi-square, Independent TTest, dan Mann Whitney. Hasil Penelitian: 40 responden yang memenuhi kriteria penelitian. Tidak didapatkan perbedaan kejadian hipertensi $(55 \%$ vs $60 \%$; p-value : 1,000), rata-rata TDS $(138,25(24,36) \mathrm{mmHg}$ vs $144,45(20,24)$ mmHg ; p-value : 0,394) dan rata-rata TDD (85 (68 - 132) mmHg vs $83(58$ - 105) mmHg ; p-value : 0,369) yang tidak bermakna antar 2 kelompok masyarakat yang tidak pernah ke posbindu dengan yang rutin ke posbindu. Hal ini membuktikan bahwa masih banyak masyarakat yang belum terskrining dari kegiatan Posbindu dan masih sangat memerlukan Posbindu Linpung untuk menjaring lebih banyak masyarakat untuk deteksi dini PTM. Kesimpulan: Posbindu Linpung terbukti efektif dalam menjaring kasus baru penyakit tidak menular (hipertensi dan obesitas) yang berada dalam masyarakat. Hal ini terbukti dari tidak terdapat perbedaan rerata tekanan darah dari kelompok populasi yang tidak pernah melakukan skrining dengan kelompok yang rutin melakukan skrining.
\end{abstract}

Kata Kunci: hipertensi; posbindu keliling; rutin

\begin{abstract}
Non-communicable diseases (NCD) especially hypertension and cardiovascular diseases have become the highest cause of death in the world with a mortality rate of nine million deaths (44\% of all non-communicable disease deaths and $31 \%$ of all global causes of death). The purpose of this study was to determine the effectiveness of the Mobilization in Utilization Of Community Participation (Mobilization POSBINDU) activities to detect risk factor and early diagnosis of non-communicable diseases (NCD) especially hypertension. Methods: Cross-sectional method was applied to the society in Sector $5^{\text {th }}$ Kedaung Kaliangke District, the variables in this research were tested using the chi-square test, Independent T-test, and Mann Whitney test. Results: 40 respondents who met the study criteria. There were no differences in the incidence of hypertension (55\% vs 60\%; p-value: 1,000), average of SBP (138.25 (24.36) vs 144.45 (20.24); p-value: 0.394) and average of DBP (85 (68 -132) vs 83 (58 - 105) mmHg; p-value: 0.369) between 2 groups of people who have never been to Posbindu with those who are routinely to Posbindu. There are still many people who have not been screened from Posbindu activities and still urgently need to Mobilization in Utilization Of Community Participation Program (Posbindu Linpung) to get more people for early detection of NCD. Conclusion: Posbindu Linpung has proven effective in finding new cases of hypertension in the community. This is proven by the fact that there is no difference in the mean blood pressure of a population group that has never been screened with a group that routinely does a screening.
\end{abstract}

Keywords: mobilization posbindu ; routinely ; hypertension 


\section{PENDAHULUAN}

\section{Latar Belakang}

Penyakit tidak menular (PTM) merupakan salah satu penyebab kematian yang terbesar di dunia serta merupakan tantangan yang perlu diperhatikan pada abad ke-21. Secara global, pada tahun 2016, penyakit tidak menular menyumbang 41 juta $(71 \%)$ kematian dari 57 juta kematian. Penyebab kematian terbesar adalah penyakit kardiovaskular dan hipertensi sebesar 17,9 juta kematian (44\% dari semua kematian penyakit tidak menular dan $31 \%$ dari semua penyebab kematian global), kanker sebesar 9 juta kematian (22\% dari semua kematian penyakit tidak menular dan $16 \%$ dari semua penyebab kematian global), penyakit pernafasan kronis sebesar 3,8 juta kematian (9\% dari semua kematian penyakit tidak menular dan 7 dari semua penyebab kematian global), serta diabetes mellitus tipe 2 sebesar 1,6 juta kematian (4\% dari semua kematian penyakit tidak menular dan 3\% dari semua penyebab kematian global). Hal yang lebih mengkhawatirkan adalah $75 \%$ kasus kematian akibat penyakit tidak menular terjadi pada populasi usia dewasa muda. (Amruth et al., 2015; World Health Organization, 2014, 2016, 2018)

Penelitian WHO dan CDC memaparkan bahwa terdapat hubungan yang erat antara tingginya angka mortalitas akibat penyakit tidak menular pada kelompok usia dewasa muda dengan pendapatan negara. WHO pada tahun 2016, melaporkan bahwa $78 \%$ dari seluruh kematian akibat penyakit tidak menular serta $85 \%$ kematian kelompok usia dewasa muda akibat penyakit tidak menular terjadi pada negara-negara dengan pendapatan rendah dan menengah kebawah. Proporsi kematian pada kelompok usia dewasa muda akibat penyakit tidak menular sebesar $25 \%$ pada negara berpenghasilan tinggi, $43 \%$ pada negara berpenghasilan rendah, serta $47 \%$ pada negara berpenghasilan menengah kebawah. Angka sebaran kematian akibat penyakit tidak menular pada tiap wilayah bervariasi yaitu Afrika (22\%), Mediterania Timur (24\%) dan Asia Tenggara (23\%), serta dibandingkan dengan wilayah Amerika (15\%), Wilayah Eropa (17\%) dan Pasifik Barat $(16 \%)$. Perbedaan angka kematian akibat penyakit tidak menular ini disebabkan oleh terlambatnya deteksi dini serta pengobatan yang dijalani akibat kurangnya pengetahuan serta kewaspadaan penduduk negara menengah kebawah yang menyebabkan tingginya angka komplikasi pada penyakit tersebut. (CDC, 2014; WHO, 2016, 2018; World Health Organization, 2018)

Indonesia sendiri merupakan negara anggota ASEAN dengan pendapatan tahunan berada dalam status menengah kebawah. Menurut survei WHO tahun 2016, didapatkan penduduk populasi Indonesia mencapai 261,1 juta jiwa dengan total kematian pada tahun 2016 yaitu sebesar 1,863 juta jiwa. Proporsi kematian penduduk Indonesia umumnya didominasi oleh penyakit tidak menular dengan sebaran pada kasus penyakit jantung dan pembuluh darah sebesar 35\% total kematian, kanker sebesar 12\% total kematian, PPOK (Penyakit Paru Obstruksi Kronis) sebesar $6 \%$ total kematian, diabetes mellitus tipe 2 sebesar $6 \%$ total kematian, penyakit tidak menular lainnya sebesar $15 \%$ total kematian, masalah kesehatan ibu dan anak serta gizi sebesar $21 \%$ total kematian dan kecelakaan sebesar $6 \%$ total kematian. WHO juga memaparkan di Indonesia, kematian akibat penyakit tidak menular pada kelompok dewasa muda mencapai 1,365 juta jiwa pada tahun 2016, dengan probabilitas risiko sebesar 30\% pada laki-laki, $23 \%$ pada wanita, serta 26\% pada total populasi. (Riley \& Cowan, 2014; Schröders et al., 2017; Who, 2014; WHO, 2018)

Penyakit tidak menular ini sebenarnya dapat dicegah dengan pola hidup sehat dan dapat dicegah progresitivitasnya agar tidak terjadi komplikasi di kemudian hari. Salah satu cara untuk mendapatkan info pola hidup sehat adalah dengan mensosialisasikan kegiatan posbindu dikarenakan pada kegiatan posbindu juga dilakukannya sosialisasi mengenai gaya hidup sehat dan penyuluhan masalah kesehatan strategis pada kurun waktu tertentu. Posbindu sendiri merupakan 
ujung tombak utama dalam melakukan tindakan skrining atau deteksi dini dari penyakit tidak menular agar tidak terjadi komplikasi di kemudian hari. (Kemenkes, 2019)

Pos Pembinaan Terpadu (Posbindu) merupakan sebuah program kesehatan dari pemerintah yang menitikberatkan peran serta masyarakat (kader) dalam kegiatan promosi kesehatan, deteksi dini penyakit, pemantauan, pencegahan komplikasi, serta tindak lanjut dini terhadap faktor-faktor risiko penyakit tidak menular secara menyeluruh, mandiri, serta berkesinambungan. Tujuan dari kegiatan posbindu sendiri adalah untuk meningkatkan kewaspadaan masyarakat terhadap faktor risiko penyakit tidak menular melalui pemberdayaan masyarakat, serta deteksi dini penyakit tidak menular agar tidak terjadi komplikasi yang fatal. Sasaran kegiatan Posbindu PTM bukanlah masyarakat yang sakit saja melainkan masyarakat yang sehat, risiko tinggi dan rendah, serta penyandang PTM mulai usia 15 tahun. (Kementerian Kesehatan RI, 2012; Nugraheni \& Hartono, 2018b, 2018a)

Posbindu sebenarnya merupakan sebuah program yang sangat baik untuk deteksi dini penyakit tidak menular, tetapi kenyataan di lapangan sangatlah ironis. Penelitian yang dipublikasikan tentang Posbindu masih jarang, tetapi studi pendahuluan di Posbindu wilayah studi, menunjukkan bahwa, hanya sebanyak 10\% dari populasi lokal menggunakan layanan Posbindu. Posbindu dianggap bergabung dengan perawatan kesehatan sosial geriatri, karena pengguna utama adalah populasi geriatri. Banyak pula stigma bahwa ke posbindu hanyalah untuk orang sakit atau merasa dirinya sakit. Jurnal penelitian Posbindu lainnya mengungkapkan kurangnya partisipasi masyarakat terhadap kegiatan Posbindu adalah kurangnya pengetahuan masyarakat, kurangnya kewaspadaan masyarakat terhadap penyakit tidak menular, sikap dan perilaku yang kurang baik, peran serta tokoh masyarakat dan masih banyak lainnya. (Kiting et al., 2017; Melita \& Nadjib, 2018; Nasruddin, 2017; Primiyani et al., 2019; Rahmayanti \& Hargono, 2017; Sari \& Mieke, 2018; Sunartyasih \& Linda, 2010; Suparto et al., 2015)

Posbindu Keliling Kampung (Posbindu LinPung) merupakan sebuah inovasi dari Puskesmas Kedaung Kaliangke untuk menjaring masyarakat langsung dari rumah ke rumah serta pintu ke pintu untuk dilakukan pemeriksaan dini atau skrining penyakit tidak menular kepada masyarakat yang tidak pernah hadir ke Posbindu serta meningkatkan kesadaran masyarakat tentang pentingnya pemeriksaan rutin terhadap penyakit tidak menular secara rutin dan berkala. Penelitian ini diangkat untuk melihat perbedaan tekanan darah, indeks massa tubuh (IMT), lingkar pinggang, kejadian hipertensi, serta kejadian obesitas pada kelompok yang tidak pernah kontrol ke Posbindu dibandingkan masyarakat yang rutin kontrol ke Posbindu. Penelitian ini diangkat pula untuk mematahkan stigma masyarakat bahwa kontrol kesehatan hanyalah untuk orang-orang dengan gejala serta mengubah paradigma sakit masyarakat menjadi paradigma sehat.

\section{Rumusan Masalah}

Untuk melihat efektivitas dari program Posbindu Keliling dalam menjaring kasus baru penyakit tidak menular khususnya hipertensi dan obesitas

\section{METODE PENELITIAN}

Penelitian ini merupakan penelitian pendahuluan berupa penelitian observasional - survei yang dilaksanakan di RW 005 Kelurahan Kedaung Kaliangke, Kecamatan Cengkareng pada periode 26 November 2019. Sampel penelitian ini adalah masyarakat mulai usia 15 tahun, penduduk RW 005, Kelurahan Kedaung Kaliangke, Kecamatan Cengkareng yang selanjutnya dibagi menjadi 2 kelompok yaitu masyarakat yang rutin ke Posbindu RW 005 dan masyarakat yang tidak pernah 
hadir ke Posbindu RW 005. Perkiraan besar sampel pada penelitian ini yaitu sebesar 90 responden dengan metode pengambilan sampel berupa total sampling, mengacu pada jumlah responden yang hadir rutin ke Posbindu RW 005. Kriteria inklusi dalam penelitian ini adalah semua masyarakat mulai usia 15 tahun, tanpa memandang jenis kelamin, pekerjaan, ras, Indeks Massa Tubuh (IMT), gaya hidup, menderita riwayat penyakit kronik, dan konsumsi obat-obatan rutin. Kriteria eksklusi pada penelitian ini adalah masyarakat yang menolak dilakukan pemeriksaan atau tidak kooperatif saat pengukuran. Analisis statistik menggunakan uji statistik Chi square with Yates Correction dengan Uji alternatif Fisher Exact untuk skala data nominal-nominal, serta uji statistik Independent T-Test dengan uji alternatif Mann-Whitney untuk skala data nominal-numerik. Adanya perbedaan antar 2 kelompok disimpulkan jika nilai $p$-value $<0,05$ dan tidak adanya perbedaan antar 2 kelompok disimpulkan jika nilai $p$-value $\geq 0,05$. Penelitian ini dilakukan oleh dokter internship dengan surat tugas dokter internship bernomor DG.02.04/2.1/5607/2019 yang telah dilampirkan kepada redaksi.

\section{HASIL DAN PEMBAHASAN}

Penelitian ini adalah penelitian pendahuluan untuk melihat efektivitas posbindu keliling dalam menjaring kejadian kasus baru hipertensi dan obesitas. Penelitian berlangsung dengan mengikutsertakan 40 responden dengan 20 responden yang rutin kontrol ke Posbindu RW 005 serta 20 responden yang tidak pernah kontrol ke Posbindu RW 005. Hasil skrining penderita hipertensi dengan Program Posbindu Keliling Kampung didapatkan penderita hipertensi sejumlah $11(55 \%)$ responden. Angka ini tidak berbeda jauh dengan angka hipertensi masyarakat yang rutin ke Posbindu yaitu sebesar $12(60 \%)$ responden. Hasil skrining status gizi dengan Program Posbindu Keliling Kampung yaitu sebesar 8 (40\%) responden. Hasil uji statistik Chi Square with Yates's Correction didapatkan tidak terdapat perbedaan bermakna antara penderita hipertensi dan obesitas pada kelompok masyarakat yang tidak pernah ke Posbindu dengan kelompok masyarakat yang rutin ke Posbindu ( $p$-value : 1,000 vs 0,343) (tabel 1).

Tabel 1. Distribusi Kejadian Hipertensi dan Obesitas di RW 05, Kelurahan Kedaung Kaliangke

\begin{tabular}{llccc}
\hline \multirow{2}{*}{ Parameter } & & $\begin{array}{c}\text { Tidak Rutin } \\
\text { Posbindu }\end{array}$ & Rutin Posbindu & \multirow{2}{*}{$\boldsymbol{P}^{*}$} \\
\cline { 3 - 4 } & & $\mathbf{N}$ & $\mathbf{N}$ & \\
\hline \multirow{2}{*}{ Tekanan Darah } & Hipertensi & 11 & 12 & 1,000 \\
\multirow{2}{*}{ Status Gizi } & Normal & 9 & 8 & \\
& Obesitas & 8 & 12 & 0,343 \\
\hline & Normal & 12 & 8 & \\
\hline
\end{tabular}

Analisis data numerik TDS didapatkan bahwa rata-rata tekanan darah sistolik masyarakat yang tidak pernah ke Posbindu sebesar 138,25 $(24,36) \mathrm{mmHg}$ yang tidak berbeda jauh hasilnya dengan masyarakat yang rutin ke Posbindu sebesar $144,45(20,24) \mathrm{mmHg}$. Walaupun secara nilai rata-rata tekanan darah sistolik dapat dilihat bahwa masyarakat yang tidak pernah ke Posbindu memiliki TDS yang lebih rendah sebesar $6,1(7,08) \mathrm{mmHg}$ bilamana dibandingkan dengan masyarakat yang rutin ke Posbindu, tetapi secara uji statistik Independent T-test dapat dilihat bahwa tidak terdapat perbedaan rerata tekanan darah yang bermakna antara masyarakat yang tidak pernah ke posbindu dengan yang rutin ke posbindu ( $p$-value : 0,394). Data sebaran univariat pada tabel 1 juga memaparkan ternyata terdapat nilai TDS yang cukup mengkhawatirkan pada kelompok masyarakat yang tidak pernah ke Posbindu yaitu TDS sebesar $175 \mathrm{mmHg}$ yang tentu saja jika hal 
ini dibiarkan akan berdampak meningkatnya komplikasi serta angka morbiditas dan mortalitas akibat penyakit tidak menular (Tabel 2).

Analisis data numerik TDD didapatkan hasil yang cukup mengkhawatirkan, didapatkan hasil bahwa tekanan darah distolik memiliki sebaran data yang tidak normal menurut uji Normalitas Shapiro Wilk ((p-value : 0,032), hal ini terjadi dikarenakan pada pengukuran TDD masyarakat yang tidak pernah ke Posbindu didapatkan hasil TDD yang sangat tinggi yaitu mencapai 132 $\mathrm{mmHg}$ dan ini merupakan sesuatu yang sangat membahayakan dikarenakan sudah jatuh ke dalam kasus hipertensi urgensi tetapi tidak ada gejala penyerta apapun yang dialami oleh penderitanya. Hasil data univariat didapatkan bahwa masyarakat yang tidak pernah ke Posbindu memiliki ratarata tekanan darah diastolik sebesar $85(68$ - 132) $\mathrm{mmHg}$ serta lebih tinggi bila dibandingkan masyarakat yang rutin ke posbindu dengan rata-rata tekanan darah diastolik sebesar $35(58-105)$ mmHg. Hasil uji statistik alternatif Mann Whitney didapatkan hasil tidak terdapat perbedaan rerata TDD yang bermakna antara kelompok masyarakat yang tidak pernah ke posbindu dengan masyarakat yang rutin ke posbindu (p-value : 0,369), serta ditemukan bahwa TDD kelompok masyarakat yang tidak pernah ke posbindu jauh lebih mengkhawatirkan dibanding dengan kelompok masyarakat yang rutin ke posbindu. (Tabel 2)

Tabel 2. Perbedaan Tekanan Darah Sistolik, Tekanan Darah Diastolik, Berat Badan, Tinggi Badan, Indeks Massa Tubuh, dan Lingkat Pinggang Antar 2 Kelompok Masyarakat di RW 05, Kelurahan Kedaung Kaliangke

\begin{tabular}{|c|c|c|c|c|c|c|}
\hline \multicolumn{2}{|c|}{ Parameter } & Normalitas & $\begin{array}{c}\text { Mean } \\
\text { (SD) }\end{array}$ & $\begin{array}{c}\text { Med } \\
\text { (Min-Max) }\end{array}$ & $\begin{array}{l}\text { MD (SE) } \\
\text { (CI 95\%) }\end{array}$ & $\begin{array}{c}p- \\
\text { value }\end{array}$ \\
\hline $\begin{array}{c}\text { Tekanan } \\
\text { Darah } \\
\text { Sistolik }\end{array}$ & $\begin{array}{c}\text { Tidak Pernah ke } \\
\text { Posbindu } \\
\text { Rutin Posbindu }\end{array}$ & 0,403 & $\begin{array}{l}138,35 \\
(24,36) \\
144,45 \\
(20,24)\end{array}$ & $\begin{array}{c}139 \\
(99-175) \\
143,5 \\
(114-179)\end{array}$ & $\begin{array}{c}-6,1(7,08) \\
(-20,44- \\
8,24)\end{array}$ & $0,394^{*}$ \\
\hline $\begin{array}{c}\text { Tekanan } \\
\text { Darah } \\
\text { Diastolik }\end{array}$ & $\begin{array}{l}\text { Tidak Pernah ke } \\
\text { Posbindu } \\
\text { Rutin Posbindu }\end{array}$ & 0,868 & $\begin{array}{c}88,2 \\
(14,62) \\
82,9 \\
(11,17)\end{array}$ & $\begin{array}{c}85 \\
(68-132) \\
83 \\
(58-105)\end{array}$ & - & $0,369^{* *}$ \\
\hline $\begin{array}{l}\text { Berat } \\
\text { Badan }\end{array}$ & $\begin{array}{l}\text { Tidak Pernah ke } \\
\text { Posbindu } \\
\text { Rutin Posbindu }\end{array}$ & 0,039 & $\begin{array}{c}59,88 \\
(10,7) \\
59,75 \\
(11,04)\end{array}$ & $\begin{array}{c}61,1 \\
(40,3-76,6) \\
58 \\
(45-86)\end{array}$ & - & $0,718^{* *}$ \\
\hline $\begin{array}{l}\text { Tinggi } \\
\text { Badan }\end{array}$ & $\begin{array}{l}\text { Tidak Pernah ke } \\
\text { Posbindu } \\
\text { Rutin Posbindu }\end{array}$ & 0,323 & $\begin{array}{c}153,15 \\
(8,42) \\
150,4(6,2)\end{array}$ & $\begin{array}{c}151,5 \\
(142-169) \\
151,5 \\
(140-160)\end{array}$ & $\begin{array}{c}2,75(2,34) \\
(-1,98-7,48)\end{array}$ & $0,247^{*}$ \\
\hline IMT & $\begin{array}{l}\text { Tidak Pernah ke } \\
\text { Posbindu } \\
\text { Rutin Posbindu }\end{array}$ & 0,805 & $\begin{array}{l}25,74 \\
(5,45) \\
26,52 \\
(5,11)\end{array}$ & $\begin{array}{c}24,27 \\
(15,63-35,33) \\
26,03 \\
(17,80-37,22)\end{array}$ & $\begin{array}{c}0,78(1,67) \\
(-4,16-2,60)\end{array}$ & $0,642^{*}$ \\
\hline $\begin{array}{l}\text { Lingkar } \\
\text { Pinggang }\end{array}$ & $\begin{array}{l}\text { Tidak Pernah ke } \\
\text { Posbindu } \\
\text { Rutin Posbindu }\end{array}$ & 0,872 & $\begin{array}{c}86,3(9,67) \\
89,45 \\
(10,37) \\
\end{array}$ & $\begin{array}{c}88,5 \\
(64-101) \\
91 \\
(67-113) \\
\end{array}$ & $\begin{array}{c}-3,15(3,17) \\
(-9,57-3,27)\end{array}$ & $0,327^{*}$ \\
\hline
\end{tabular}

Sampai saat ini belum ada penelitian yang membahas mengenai efektif atau tidaknya posbindu keliling dalam menemukan kasus baru penyakit tidak menular khususnya hipertensi dan obesitas. Penelitian ini merupakan penelitian pendahuluan untuk melihat apakah sebenarnya kasus penyakit 
tidak menular di masyarakat dengan kesadaran control kesehatan yang kurang berbeda signifikan atau tidak dengan kasus penyakit tidak menular pada kelompok masyarakat yang memiliki kesadaran control kesehatan yang tinggi. Kesadaran control masyarakat dilihat dari minat menghadiri posbindu yang dilaksanakan tiap bulan. Kesadaran masyarakat yang tinggi cenderung hadir ke Posbindu, sedangkan kesadaran masyarakat yang kurang cenderung tidak peduli dan tidak hadir pada kegiatan Posbindu. Oleh karena itu Posbindu keliling menjadi alternatif utama untuk menjaring kasus baru penyakit tidak menular pada kelompok masyarakat yang tidak rutin ke Posbindu serta memiliki kesadaran control kesehatan yang kurang.

Hasil penelitian ini menunjukan bahwa angka kejadian hipertensi dan obesitas pada kelompok masyarakat yang rutin dan tidak rutin ke Posbindu adalah tidak berbeda signifikan. Ini membuktikan bahwa prevalensi penyakit tidak menular merupakan sebuah fenomena gunung es yaitu sebuah fenomena dimana sebenarnya prevalensi masyarakat yang mengalami penyakit tidak menular adalah lebih banyak melampaui angka yang tercatat dalam data kesehatan. Posbindu Keliling menjadi program yang baik dimana dapat menjangkau dan deteksi dini penyakit tidak menular pada kelompok masyarakat yang memiliki kesadaran kurang terhadap kesehatan serta dapat juga menjadi media penyuluhan yang efektif guna meningkatan pengetahuan masyarakat.

Menurut data Kemenkes RI yang dirilis sejak tahun 2013 hingga 2018, menyatakan bahwa prevalensi Penyakit tidak menular di Indonesia paling banyak adalah hipertensi yang sebaran 9,3\% hingga 25,8\% dan terus meningkat kejadiannya dari waktu ke waktu. Peningkatan angka kejadian hipertensi sendiri disebabkan mulai dari faktor internal masyarakat yaitu mulai dari perubahan gaya hidup menjadi lebih sentinel, hedonisme, serta diet yang tidak sehat. Walaupun dari data statistik dapat dilihat bahwa sudah sangat banyak populasi yang terjaring dengan diagnosa hipertensi, tetapi hal ini masih merupakan fenomena gunung es dimana masih banyak populasi masyarakat yang belum pernah terpapar tenaga kesehatan untuk skrining penyakit tidak menular. Hal ini menyebabkan bahwa sebenarnya prevalensi nyata penyakit tidak menular di masyarakat jauh lebih tinggi daripada yang sudah tercatat. Hipertensi merupakan salah satu penyakit yang memiliki komplikasi jangka panjang yang cukup berat dan dapat menjadi beban baik bagi negara terkait pembiayaan dan bagi penderitanya itu sendiri terkait kualitas hidup. Oleh karena itu, deteksi dini penyakit tidak menular sebelum terjadi komplikasi merupakan hal yang mutlak diperlukan. (Badan Penelitian dan Pengembangan Kesehatan, 2013; Balitbang Kemenkes RI, 2018; Kemenkes RI, 2018; Riskesdas, 2018)

Posbindu merupakan sebuah program pemerintah yang telah diamanatkan oleh perundanganundangan khususnya Undang-Undang RI No. 36 Tahun 2009 Perihal Kesehatan yang tertuang dalam pasal 158 ayat 1 , menyatakan bahwa pemerintah, pemerintah daerah dan masyarakat melakukan upaya pencegahan, pengendalian dan penanganan PTM beserta akibat yang ditimbulkan. (Kementerian Kesehatan RI, 2012; Nasruddin, 2017)

Pos Pembinaan Terpadu Penyakit Tidak Menular (Posbindu PTM) adalah sebuah unit kegiatan yang melibatkan peran serta masyarakat dalam melakukan promosi kesehatan, deteksi dini penyakit, pemantauan, pencegahan komplikasi, serta tidak lanjut dini terhadap faktor-faktor risiko penyakit tidak menular secara menyeluruh, terpadu, rutin, mandiri, serta berkesinambungan. Pengembangan Program Posbindu PTM sedang gencar dilakukan oleh Kecamatan Cengkareng dengan harapan Posbindu PTM dapat dijadikan sarana serta "Mesin" untuk mengendalikan 
penyakit tidak menular yang terjadi di masyarakat mulai dari fase awal hingga fase akhir dari penyakit tidak menular. (Kementerian Kesehatan RI, 2012)

Rekomendasi WHO yang diadopsi oleh Pemerintah DKI Jakarta Khususnya Kecamatan Cengkareng adalah Program Upaya Kesehatan Berbasis Masyarakat (UKBM) yang memusatkan pencegahan serta penanggulangan PTM melalui 3 komponen basis utama yaitu surveilans faktorfaktor risiko potensial terjadinya PTM, kegiatan promosi kesehatan, dan pencegahan penyakit tidak menular melalui inovasi dan reformasi sistem manajemen pelayanan kesehatan yaitu Posbindu PTM. Pelaksanaan kegiatan surveilans faktor-faktor risiko potensial terjadinya PTM berbasis Posbindu dilakukan dengan cara pengukuran dan pencatatan data peserta Posbindu yang hadir saat kegiatan Posbindu berlangsung, serta pengolahan, analisis data, interpretasi data dan diseminasi informasi dilakukan ketika Posbindu diselenggarakan. Semua informasi dn data yang didapatkan dari Posbindu merupakan data yang sangat penting dan akurat dalam menentukan strategi dan prioritas masalah dalam pengambilan keputusan program kerja yang berjalan dalam sebuah wilayah. (Kementerian Kesehatan RI, 2012; World Health Organization, 2018)

Kegiatan Posbindu PTM dan surveilans Faktor risiko PTM berbasis Posbindu sendiri sebenarnya telah dilakukan oleh Puskesmas Kedaung Kaliangke sejak beberapa tahun yang lalu. Posbindu PTM Puskesmas Kedaung Kaliangke pun terus bertambah dari tahun ke tahun melalui pelatihan kader secara berkala dan mandiri. Data terakhir mengatakan bahwa Puskesmas Kedaung Kaliangke sendiri sekarang sudah memiliki 8 Posbindu PTM yang mewakili 10 RW cakupan Kelurahan Kedaung Kaliangke. Dibalik seluruh program kegiatan Puskesmas Kedaung Kaliangke yang sudah baik tetapi kenyataan di lapangan mengatakan bahwa capaian jumlah minimal cakupan penduduk usia mulai 15 tahun yang menggunakan fasilitas Posbindu PTM masih sangat sedikit. Hal ini menjadikan fungsi Posbindu sebagai sarana untuk deteksi dini penyakit serta sarana untuk mengidentifikasi faktor risiko PTM masyarakat menjadi kurang optimal.

Minimalnya partisipasi masyarakat dalam kegiatan Posbindu PTM disebabkan oleh berbagai macam faktor yang berperan, mulai dari pengetahuan dan sikap masyarakat yang buruk, anggap bahwa ke Posbindu hanya untuk orang yang sakit saja atau sudah usia lanjut, dukungan keluarga dan lingkungan, peran serta tokoh masyarakat dan kader, tingkat pendidikan dan pendapatan, jarak tempuh ke tempat Posbindu PTM, dan masih banyak lagi (Fuadah et al., 2018; Sari \& Mieke, 2018; Umayana \& Cahyati, 2015). Antisipasi dari minimalnya partisipasi masyarakat ini adalah dengan dibentuknya Pos Pembinaan Terpadu Penyakit Tidak Menular Keliling Kampung (Posbindu PTM LinPung). Posbindu PTM LinPung sendiri adalah inovasi Puskesmas Kedaung Kaliangke untuk memberikan edukasi, pemahaman, serta pelayanan kepada masyarakat dari rumah ke rumah serta dari pintu ke pintu secara perorangan dan berbasis keluarga agar dapat menjaring masyarakat lebih luas dan melakukan deteksi dini penyakit penyakit tidak menular secara lebih akurat dan mendetail, serta untuk kegiatan surveilans faktor-faktor risiko yang berperan dalam penyakit tidak menular di masyarakat. Hasil efektivitas dari kegiatan Posbindu PTM Linpung sendiri sudah dapat dilihat dari hasil skrining penderita hipertensi sejumlah 11 (55\%) responden yang memiliki nilai proporsi lebih dari 2 kali lipat dari basis data penderita hipertensi secara nasional yaitu 25,8\%, serta penemuan kasus hipertensi urgensi yang terjadi di populasi masyarakat yang tidak pernah terjaring atau berkunjung ke Posbindu PTM maupun fasilitias kesehatan lainnya (Balitbang Kemenkes RI, 2018; Kemenkes RI, 2018; Riskesdas, 2018; WHO, 2018). 


\section{KESIMPULAN DAN SARAN}

Posbindu Linpung terbukti efektif dalam menjaring kasus baru penyakit tidak menular (hipertensi dan obesitas) yang berada dalam masyarakat. Hal ini terbukti dari tidak terdapat perbedaan rerata tekanan darah dari kelompok populasi yang tidak pernah melakukan skrining dengan kelompok yang rutin melakukan skrining.

\section{Ucapan Terima Kasih (Acknowledgement)}

Ucapan Terimakasih kasih kami haturkan sebesar-besarnya bagi seluruh pihak yang turut serta dalam selesainya penelitian ini. Terimakasih kepada dr. Wisnu Eko Prasetyo selaku Kepala Puskesmas Kecamatan Cengkareng yang telah memberikan izin penelitian, Ibu Sunarti selaku pemegang program penyakit tidak menular dan posbindu PTM Puskesmas Kedaung Kaliangke, dan seluruh karyawan Puskesmas Kedaung Kaliangke.

\section{REFERENSI}

Amruth, M., Mullick, S., Balakrishna, A., \& Prabhudeva, M. (2015). Assessment of awareness about cardiovascular disease risk factors and association between overweight and family history of cardiovascular disease among first-year medical students of a medical college in Karnataka. International Journal of Medical Science and Public Health. https://doi.org/10.5455/ijmsph.2015.1709201425 (Diakses pada tanggal 10 Desember 2019)

Badan Penelitian dan Pengembangan Kesehatan. (2013). Riset Kesehatan Dasar 2013. Riset Kesehatan Dasar 2013. http://kesga.kemkes.go.id/images/pedoman/Data\%20Riskesdas\%202013.pdf (Diakses pada tanggal 10 Desember 2019)

Balitbang Kemenkes RI. (2018). RISKESDAS 2018. In Kementrian Kesehatan Republik Indonesia. https://doi.org/1 Desember 2013 (Diakses pada tanggal 10 Desember 2019)

CDC. (2014). CDC global noncommunicable diseases (NCDs). Global Health - Health Protection. https://www.who.int/docs/default-source/ncds/9789241514620eng.pdf?sfvrsn=48f7a45c_2\&download=true (Diakses pada tanggal 10 Desember 2019)

Fuadah, D. Z., Furi, N., Prodi, R., Keperawatan, S., Karya, S., \& Kediri, H. (2018). PEMANFAATAN POS PEMBINAAN TERPADU (POSBINDU) PENYAKIT TIDAK MENULAR (PTM) PADA PENDERITA HIPERTENSI (Utilization Of Integrated Posted Cooperation (Posbindu) of Non-Communicable Disease of Patients with Hypertension). Jurnal Ners Dan Kebidanan. https://doi.org/10.26699/jnk.v5i1.ART.p020-028 (Diakses pada tanggal 10 Desember 2019)

Kemenkes. (2019). Buku pedoman manajemen penyakit tidak menular. 2 http://p2ptm.kemkes.go.id/uploads/VHcrbkVobjRzUDN3UCs4eUJ0dVBndz09/2019/03/Bu ku_Pedoman_Manajemen_PTM.pdf (Diakses pada tanggal 12 Mei 2020)

Kemenkes RI. (2018). Laporan Nasional RISKESDAS 2018. In Riskesdas 2018.

Kementerian Kesehatan RI. (2012). Petunjuk Teknis Pos Pembinaan Terpadu Penyakit Tidak Menular (Posbindu PTM). In Ditjen Pengendalian Penyakit dan Penyehatan Lingkungan, Kementerian Kesehatan RI. (Diakses pada tanggal 10 Desember 2019)

Kiting, R. P., Ilmi, B., \& Arifin, S. (2017). FAKTOR YANG BERHUBUNGAN DENGAN KINERJA KADER POSBINDU PENYAKIT TIDAK MENULAR. Jurnal Berkala Kesehatan. https://doi.org/10.20527/jbk.v1i2.3149 (Diakses pada tanggal 10 Desember 
2019)

Melita, \& Nadjib, M. (2018). Faktor-faktor yang berhubungan dengan kunjungan lansia ke posbindu lansia di wilayah kerja puskesmas kelurahan bintara kota bekasi tahun 2017. Jurnal Kebijakan Kesehatan Indonesia. https://jurnal.ugm.ac.id/jkki/article/view/26409 (Diakses pada tanggal 10 Desember 2019)

Nasruddin, N. R. (2017). Faktor-Faktor Yang Mempengaruhi Pemanfaatan Pos Pembinaan Terpadu Penyakit Tidak Menular (POSBINDU PTM) di Wilayah Kerja Puskesmas Ballaparang Kota Makassar Tahun 2017. Skripsi. http://repositori.uin-alauddin.ac.id/6515/ (Diakses pada tanggal 10 Desember 2019)

Nugraheni, W. P., \& Hartono, R. K. (2018a). STRATEGI PENGUATAN PROGRAM POSBINDU PENYAKIT TIDAK MENULAR DI KOTA BOGOR. Jurnal Ilmu Kesehatan Masyarakat. https://doi.org/10.26553/jikm.v9i3.312 (Diakses pada tanggal 10 Desember 2019)

Nugraheni, W. P., \& Hartono, R. K. (2018b). Strategi Penguatan Program Posbindu Penyakit Tidak Menular Di Kota Bogor Strengthening Strategies Of Posbindu Program For Noncommunicable Diseases In Bogor City. Jurnal Ilmu Kesehatan Masyarakat. https://doi.org/10.26553/jikm.2018.9.3 (Diakses pada tanggal 10 Desember 2019)

Primiyani, Y., Masrul, M., \& Hardisman, H. (2019). Analisis Pelaksanaan Program Pos Pembinaan Terpadu Penyakit Tidak Menular di Kota Solok. Jurnal Kesehatan Andalas. https://doi.org/10.25077/jka.v8.i2.p399-406.2019 (Diakses pada tanggal 10 Desember 2019)

Rahmayanti, E., \& Hargono, A. (2017). Implementasi Surveilans Faktor Risiko Penyakit Tidak Menular Berbasis Posbindu Berdasarkan Atribut Surveilans. Jurnal Berkala Epidemiologi. https://pdfs.semanticscholar.org/38ca/febda72ab9aba756f20e5a8331de78f667a7.pdf (Diakses pada tanggal 10 Desember 2019)

Riley, L., \& Cowan, M. (2014). Noncommunicable Diseases (NCD) Country Profiles. In WHO Document Production Services. https://doi.org/10.1057/9781137275967.0010 (Diakses pada tanggal 10 Desember 2019)

Riskesdas. (2018). Riset Kesehatan Dasar 2018. Kementrian Kesehatan Republik Indonesia. https://doi.org/1 Desember 2013 (Diakses pada tanggal 10 Desember 2019)

Sari, D. W. R., \& Mieke, S. (2018). Faktor-faktor yang berhubungan dengan pemanfaatan posbindu penyakit tidak menular (ptm) di wilayah kerja Puskesmas Kecamatan Setiabudi Kota Jakarta Selatan tahun 2018. Jurnal Kebijakan Kesehatan Indonesia: JKKI. https://doi.org/10.22146/jkki.36849 (Diakses pada tanggal 10 Desember 2019)

Schröders, J., Wall, S., Hakimi, M., Dewi, F. S. T., Weinehall, L., Nichter, M., Nilsson, M., Kusnanto, H., Rahajeng, E., \& Ng, N. (2017). How is Indonesia coping with its epidemic of chronic noncommunicable diseases? A systematic review with meta-analysis. In PLoS ONE. https://doi.org/10.1371/journal.pone.0179186 (Diakses pada tanggal 10 Desember 2019)

Sunartyasih, C. M. R., \& Linda, B. (2010). Hubungan Kendala Pelaksanaan Posbindu dengan Kehadiran Lansia di RW 08 Kelurahan Palasari Kecamatan Cibiru Kota Bandung. Sains, Teknologi, Dan Kesehatan. http://proceeding.unisba.ac.id/index.php/sains_teknologi/article/view/699 (Diakses pada tanggal 10 Desember 2019) 
Suparto, T. A., Sunjaya, D. K., \& Susanti, R. D. (2015). MASALAH-MASALAH PROGRAM POSBINDU DI DESA DAYEUHKOLOT KABUPATEN BANDUNG JAWA BARAT. JURNAL PENDIDIKAN KEPERAWATAN INDONESIA. https://doi.org/10.17509/jpki.v1i1.1185 (Diakses pada tanggal 10 Desember 2019)

Umayana, H. T., \& Cahyati, W. H. (2015). DUKUNGAN KELUARGA DAN TOKOH MASYARAKAT TERHADAP KEAKTIFAN PENDUDUK KE POSBINDU PENYAKIT TIDAK MENULAR. Jurnal Kesehatan Masyarakat. https://doi.org/10.15294/kemas.v11i1.3521 (Diakses pada tanggal 10 Desember 2019)

Who. (2014). WHO Country Cooperation Strategy 2014-2019 - Indonesia. In Country Cooperation Strategy. (Diakses pada tanggal 10 Desember 2019)

WHO. (2016). A guide to implementation research in the prevention and control of noncommunicable diseases. In World Health Organization. https://doi.org/10.1136/bmj.11868 (Diakses pada tanggal 10 Desember 2019)

WHO. (2018). Noncommunicable Diseases Country Profiles 2018. In World Health Organization. https://doi.org/16/j.jad.2010.09.007 (Diakses pada tanggal 10 Desember 2019)

World Health Organization. (2014). Noncommunicable Diseases Country Profiles 2014. In WHO Media Centre. (Diakses pada tanggal 10 Desember 2019)

World Health Organization. (2016). Proportional mortality (\% of total deaths, all ages). World Health Organization. (Diakses pada tanggal 10 Desember 2019)

World Health Organization. (2018). Noncommunicable Diseases Country Profiles 2018. In World Health Organization. https://doi.org/16/j.jad.2010.09.007 